\title{
Prothrombin time (PT), activated partial thromboplastin time (APTT) and international normalized ratio (INR) as predictive factors of coagulopathy in newly diagnosed hypertensive patients
}

\begin{abstract}
Introduction: Hypertension is major and leading cause of cardiovascular diseases. Abnormal and irregular coagulation parameters indicates predisposition to atherosclerosis but is diagnosed usually after any unwanted event; for example myocardial infarction, cerebral bleeding etc.
\end{abstract}

Objective: The main aim of the study is to evaluate prothrombin time, activated partial thromboplastin time and international normalized ratio in newly diagnosed hypertensive patients to see their predisposition towards coagulopathy in early stage.

Methods and materials: This study was conducted at Department of Pathology and Pakistan Institute of Medical Sciences, Islamabad. It includes 56patients (newly diagnosed hypertensive patients) and 65 as a control group. Ratio of male (71 patients/58.19\%) was greater than female (61patients/41.81\%). Blood pressure of all patients was measured with hypertensive criterion as systolic blood pressure $>139 \mathrm{mmHg}$ and diastolic blood pressure $>89 \mathrm{mmHg}$ for at least 3 consecutive readings. Prothrombin time activated partial thromboplastin time and international normalized ratio ware measured in all patients. Data was collected and analyzed in SPSS version 20.0 .

Results: All coagulation parameters were higher in hypertensive group with mean PT of $15.07 \pm 1.92$ seconds $(p=0.02)$, APTT $37.14 \pm 4.06$ seconds $(p=0.001)$ and INR $1.04 \pm 0.18(\mathrm{p} \leq 0.001)$, in contrast to control group having mean PT $12.36 \pm 0.74$ seconds, APTT $30.4 \pm 2.39$ seconds and INR $0.87 \pm 0.07$

Conclusion: The evaluation of coagulation parameters in newly diagnosed hypertensive patients showed significant rise which indicated their susceptibility towards coagulopathy and hemostatic abnormalities.

Keywords: hypertension, coagulopathy, myocardial infarction, atherosclerosis, thrombogenicity
Volume 4 Issue 3 - 2017

\begin{abstract}
Ali Jiskani S,' Shafia Memon, ${ }^{2}$ Lubna Naseem' 'Department of Hematology, Shaheed Zulfiqar Ali Bhutto Medical University, Pakistan

${ }^{2}$ Department of Medicine, Shaheed Zulfiqar Ali Bhutto Medical University, Pakistan
\end{abstract}

\section{Correspondence: Shahzad Ali Jiskani, Department of} Hematology, Shaheed Zulfiqar Ali Bhutto Medical University/ Pakistan Institute of Medical Sciences, G-8 Markaz, Islamabad, Pakistan, Tel +923332672268,

Email shahzadbaloach289@gmail.com

Received: January 10, 2017 | Published: April 25, 2017
Abbreviation: PT, prothrombin time; APTT, activated partial thromboplastin time; INR, international normalized ratio; VWFpp, vWF pro-peptide

\section{Introduction}

Hypertension is a rapidly mounting disease worldwide and contributes to large number of mortalities and morbidities. Obesity, lifestyle, age, gender, environmental and genetic aspects plays important role in development of hypertension. Usually hypertension present with complication and unwanted events; for example myocardial infarction and cerebral hemorrhage. ${ }^{1,2}$ Cardiovascular diseases are the main cause for the majority of deaths with arterial hypertension being one of the most frequent risk factors. ${ }^{3-5}$ Coagulopathy and hemostatic dysfunctions are among common complications of hypertension. PT and APTT are basic coagulation tests which measure integrated actions of majority of coagulation factors in extrinsic and intrinsic pathways of coagulation cascade of blood. ${ }^{6,7}$ Hypertension, a silent disease and is diagnosed at a delayed stage in the majority when complications develop, requiring immediate treatment. ${ }^{8}$ Evaluation of these hazardous factors at beginning is essential as to prevent coagulation disorders and hemostatic abnormalities. Atherosclerosis is the main fate of disturbed coagulation which ultimately leads to life threatening events. Development of thrombosis medicated acute coronary events depends on composition and liability of plaque. Thrombogenicity of the atherosclerotic lesion depends upon the presence of tissue factor, which is a major protein in the initiation of coagulation cascade. ${ }^{9}$ Lesions present in atherosclerotic areas shows unique endothelial dysfunction including pro-inflammatory, prothrombotic and impaired barrier function. ${ }^{10}$ Elevated systolic and diastolic blood pressure are associated with deranged coagulation 
factors. ${ }^{11,12}$ Many treatment modalities have been used to control and prevent hypertension but the prevalence of hypertension is increasing day by day. ${ }^{13}$ Lifestyle modification such as diet control, weight loss and exercise are important factors to control hypertension along with antihypertensive drugs. ${ }^{14,15}$

\section{Patients and materials}

This study was conducted in a Pakistan Institute of Medical Sciences, Islamabad, including total of 122patients, in which 56 were newly diagnosed hypertensive patients and 65 as control group. The criterion for hypertension was systolic blood pressure $>139 \mathrm{mmHg}$ and diastolic blood pressure $>89 \mathrm{mmHg}$ for at least 3 consecutive readings. Patient included in hypertensive group were with the history of primary hypertension, increased blood pressure $(>140 \mathrm{mmHg}$ systolic and $>89 \mathrm{mmHg}$ diastolic blood pressure), no past or current history of any anticoagulant therapy, no history of chronic viral infection or liver disease, have not been on long term drug regimen and no underlying disease. Patients included in control group were normal blood pressure $(<140 \mathrm{mmHg}$ systolic and $<89 \mathrm{mmHg}$ diastolic blood pressure), no history of any past or recent drug therapy, no history of chronic viral or liver disorders and no any underlying cause. Blood pressure of all patients $(\mathrm{n}=122)$ were notes. Blood sample of all patients $(n=122)$ were drawn and collected in tri-sodium citrate sample bottle for evaluation of coagulation profile. Anti-coagulated samples were centrifuged at 4000 rounds per minutes for 10minutes. Prothrombin time (PT), activated partial thromboplastin time (APTT) and International Normalized Ratio (INR) were measure. The data was collected and analyzed for mean, range, standard error, standard deviation and level of significance in SPSS version 20.0. The p-value of $<0.05$ was taken statistically significant.

\section{Results}

A total of 56 patients were included in study and 65 normal adults were taken as control. Table 1 shows age of patients in both hypertensive group and control group. The age of patients in hypertensive group $(\mathrm{n}=56)$ was ranging between 31 to 85 years (Mean=54.88 \pm 13.57 years, $\mathrm{SE}=1.81$ ), while age of patients in control group $(n=65)$ was between 16 to 81years (Mean= 49.44 \pm 14.16 years, $\mathrm{SE}=1.79$ ) (Figure 1). In both groups ratio of male was slightly higher than female (Table 2). In hypertensive group $(\mathrm{n}=56), 33(58.92 \%)$ patients were male, while 23(41.07\%) were female (Figure 2). In control group ( $\mathrm{n}=65), 38(58.46 \%)$ were male and $28(41.56 \%)$ were female (Figure 3). Systolic and diastolic blood pressure was measured and evaluated in both groups (Table 3 \& 4). In control group, the systolic blood pressure measured was ranged between 106 to $138 \mathrm{mmHg}(\mathrm{Mean}=122.3 \pm 7.57 \mathrm{mmHg}, \mathrm{SE}=1.17)$ and diastolic blood pressure was between 62 to $88 \mathrm{mmHg}$ (Mean $=75.71 \mathrm{mmHg}, \mathrm{SE}=0.91)$ (Figure 4). Both systolic and diastolic blood pressures were increased in hypertensive group as compared to control group. Systolic blood pressure in hypertensive group was between 140 to $167 \mathrm{mmHg}$ (Mean=148.21 $\pm 6.05 \mathrm{mmHg}, \mathrm{SE}=0.8, \mathrm{p}=0.6$ ) and diastolic blood pressure was between 85 to $114 \mathrm{mmHg}$ (Mean=98.39 $\pm 6.34 \mathrm{mmHg}$, $\mathrm{SE}=0.84, \mathrm{p}=0.01$ ) (Figure 4). Diastolic blood pressure showed statistically significant results when compared in both groups. Coagulation parameters were measured and analyzed in both groups (Table 5 \& 6). In control group, PT was ranged between 11 to 14 seconds (Mean=12.56 \pm 0.71 seconds, $\mathrm{SE}=0.2$ ), APTT was measured between 25 to 34 seconds (Mean $=31.49 \pm 2.39$ seconds, $\mathrm{SE}=0.30$ ) and INR was between 0.6-1 (Mean=0.90 $\pm 0.07, \mathrm{SE}=0.03$ ) (Figure 5). As compared to control group, the hypertensive group showed increase in their coag8ulation parameters. PT in hypertensive group was calculated between 11 to 19 seconds (Mean=15.07 \pm 1.92 seconds, $\mathrm{SE}=0.25$, $\mathrm{p}=0.02$ ), APTT between 30 to 46 seconds (Mean $=37.14 \pm 4.06$ seconds, $\mathrm{SE}=0.54, \mathrm{p}=0.001$ ) and INR was between 0.7-1.7 (Mean=1.04, $\mathrm{SE}=0.02, \mathrm{p}=<0.001$ ) (Figure 5). All coagulation parameters showed statistically significant outcome when compared in both groups. However, age and systolic blood pressure were not statistically significant (Table 7).

Table I Comparison of age of patients in both control and hypertensive groups $(n=122)$

\begin{tabular}{lll}
\hline & $\begin{array}{l}\text { Hypertensive } \\
\text { group }(\mathbf{n = 5 6})\end{array}$ & $\begin{array}{l}\text { Control Group } \\
(\mathbf{n}=65)\end{array}$ \\
\hline Mean & 54.88 years & 49.44 years \\
Range & $31-85$ years & $16-81$ years \\
Standard deviation & 13.57 & 14.16 \\
Standard Error & 1.81 & 1.79 \\
\hline
\end{tabular}

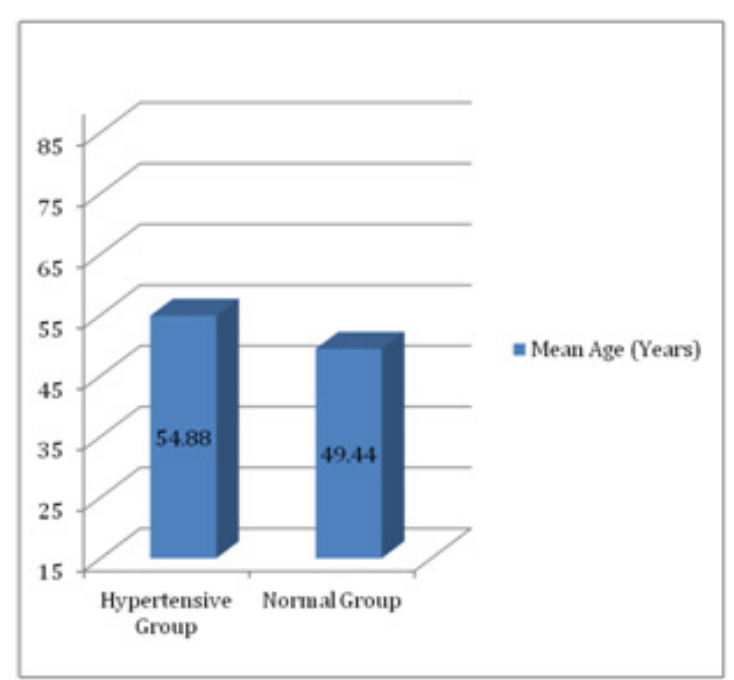

Figure I Comparison of age of patients in both hypertensive and control groups.

Table 2 Comparison of gender in both control and hypertensive groups $(n=122)$

\begin{tabular}{lll}
\hline & Hypertensive group $(\mathbf{n}=\mathbf{5 6})$ & Control group $(\mathbf{n}=\mathbf{6 5})$ \\
\hline Male & 33 & 38 \\
Female & 23 & 28 \\
\hline
\end{tabular}

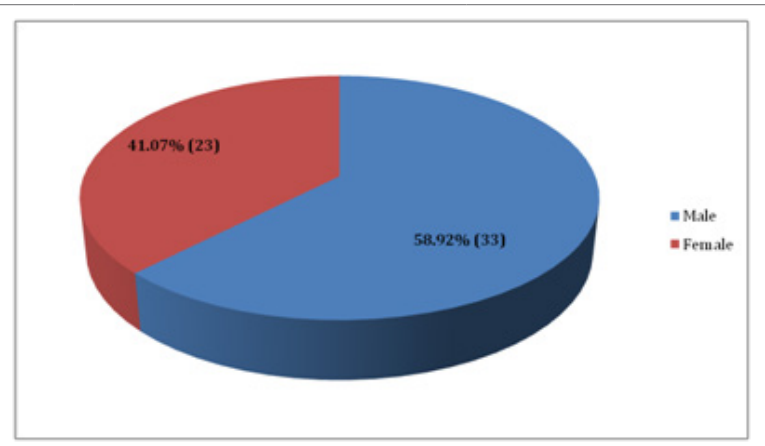

Figure 2 Comparison of gender in hypertensive group $(n=56)$. 




Figure 3 Comparison of gender in control group $(n=65)$.

Table 3 Systolic and diastolic blood pressures in control group $(n=65)$

\begin{tabular}{lll}
\hline & Systolic blood pressure & $\begin{array}{l}\text { Diastolic blood } \\
\text { pressure }\end{array}$ \\
\hline Mean & $122.30 \mathrm{mmHg}$ & $75.71 \mathrm{mmHg}$ \\
Range & $106-138 \mathrm{mmHg}$ & $62-88 \mathrm{mmHg}$ \\
Standard deviation & 7.57 & 7.57 \\
Standard error & 1.17 & 0.91 \\
\hline
\end{tabular}

Table 4 Systolic and diastolic blood pressures in hypertensive group $(n=56)$

\begin{tabular}{lll}
\hline & Systolic blood pressure & $\begin{array}{l}\text { Diastolic blood } \\
\text { pressure }\end{array}$ \\
\hline Mean & $148.21 \mathrm{mmHg}$ & $98.39 \mathrm{mmHg}$ \\
Range & $140-167 \mathrm{mmHg}$ & $85-114 \mathrm{mmHg}$ \\
Standard deviation & 6.05 & 6.34 \\
Standard error & 0.809 & 0.848 \\
\hline
\end{tabular}

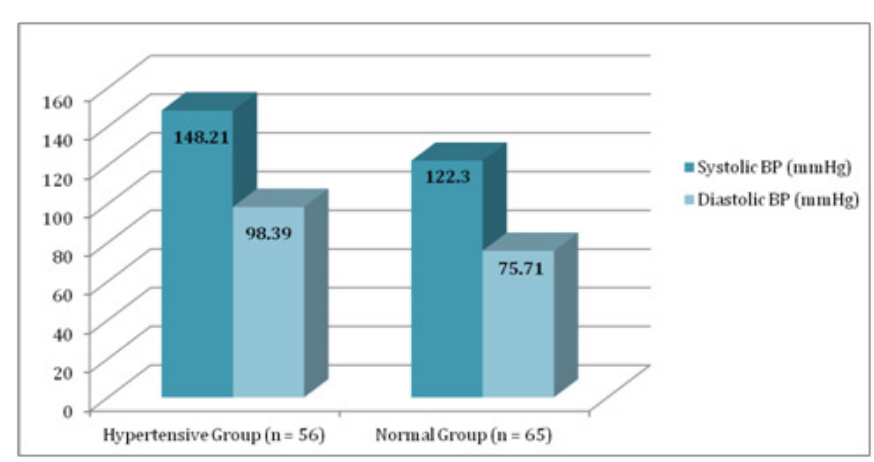

Figure 4 Systolic and diastolic pressure in both hypertensive and control groups.

Table 5 Coagulation profile in control group $(n=65)$

\begin{tabular}{llll}
\hline & PT & APTT & INR \\
\hline Mean & 12.56 & 31.49 & 0.9 \\
Range & $11-14$ & $25-34$ & $0.6-1$ \\
Standard deviation & 0.71 & 2.39 & 0.07 \\
Standard error & 0.2 & 0.3 & 0.03 \\
\hline
\end{tabular}

Table 6 Coagulation profile in hypertensive group $(n=56)$

\begin{tabular}{llll}
\hline & PT & APTT & INR \\
\hline Mean & 15.07 & 37.14 & 1.04 \\
Range & $11-19$ & $30-46$ & $0.70-1.70$ \\
Standard deviation & 1.92 & 4.06 & 0.18 \\
Standard error & 0.25 & 0.54 & 0.02
\end{tabular}



Figure 5 Coagulation profile (PT, APTT and INR) in both hypertensive and control groups.

Table 7 Correlation of age, systolic blood pressure, diastolic blood pressure and coagulation profile in both control and hypertensive groups $(n=122)$

\begin{tabular}{|c|c|c|c|}
\hline & $\begin{array}{l}\text { Hypertensive } \\
\text { group }(n=56)\end{array}$ & $\begin{array}{l}\text { Control } \\
\text { group }(n=65)\end{array}$ & P-value \\
\hline Age (Mean) & 54.88years & 49.44years & 0.613 \\
\hline $\begin{array}{l}\text { Systolic blood } \\
\text { pressure (Mean) }\end{array}$ & $148.21 \mathrm{mmHg}$ & $122.30 \mathrm{mmHg}$ & 0.7 \\
\hline $\begin{array}{l}\text { Diastolic blood } \\
\text { pressure (Mean) }\end{array}$ & $98.39 \mathrm{mmHg}$ & $75.7 \mathrm{ImmHg}$ & 0.02 \\
\hline PT (Mean) & 15.07 & 12.56 & 0.02 \\
\hline APTT (Mean) & 37.14 & 31.49 & 0.002 \\
\hline INR (Mean) & 1.04 & 0.9 & $<0.001$ \\
\hline
\end{tabular}

\section{Discussion}

Study shows a strong correlation between coagulation parameters in newly diagnosed hypertensive patients as compared to control group. Increased levels of all parameters with statistically significant difference gives an evidence of their tendency towards defects of hemostatic function. Hemostatic system is straightforwardly concerned in process of atherosclerosis production. Hypertension is key risk factor of atherosclerosis and causes endothelial dysfunction, followed by endothelial damage and platelet hyper activation. Prothrombin time and activated partial thromboplastin time are primary screening tests for coagulopathy. ${ }^{16,17}$ Factor XI wires both normal human hemostasis and pathological thrombosis. ${ }^{18}$ Factor XII catalyzes the activation of FXI, which in turn activates factor IX to FIXa, which directs to thrombin generation and fibrin formation. ${ }^{18-20}$ Von Willebrand is a protein, which assembles itself into multimers, followed by the complex cellular processing which includes dimerization in the endoplasmic reticulum, glycosylation in the endoplasmic reticulum and Golgi apparatus, multimerization in the Golgi apparatus and packaging into the storage granules. It releases vWF pro-peptide (VWFpp) and is complexed with factor VIII and circulates as a loosely coiled protein complex that does not interact 
strongly with platelets or endothelial cells under basal conditions. But in vascular injury, there is conformational changes in multimeric VWF that causes platelets to adhere, become activated and aggregate so as to present an activated platelet phospholipid surface. This facilitates clotting that is partly regulated by FVIII, showing their great tendency in defective hemostasis due to endothelial injury. ${ }^{21}$ A study by Adaeze et al. ${ }^{11}$ performed in Nigeria, showed remarkable changes in coagulation parameters among hypertensive patients but this study included newly diagnosed as well as patients with old history of hypertension greater than 5years. So coagulation factors were more deranged in patients with longer duration of hypertension which is suggestive of their increased tendency towards production of atherosclerosis. ${ }^{11}$ Another study from Lee ${ }^{22}$ showed very strong association between hypertension and hemostatic defects. Patients with hypertension are known to be at an augmented risk of both coronary artery disease and cerebrovascular disease, which are thrombotic in origin. ${ }^{22}$ There was also a relationship between systolic pressure and APTT in patients which might be due to risk factors associated with hypertension..$^{23}$ In our study, only recently diagnosed patients were assessed for PT and APTT so different results in previous studies may possibly be due to duration of hypertension, age, gender and utilization of antihypertensive drugs. PT and APTT in our results showed significantly difference as compared to control group and other studies with longer duration of hypertension. So early prediction of coagulopathy and development of atherosclerosis or other disastrous complication can be made by measuring the basic parameters by including them in routine investigation, Routine use of these parameters in hypertensive patients will help in determining the severity of development of coagulopathy and to introduce the correct time for intervention of anticoagulant drugs. This will also give a way towards further investigating the patient or to reduce the extra burden of less related and unrelated investigations; therefore reducing the cost burden on patient and having good time to prevent the complications. Although, study shows statistically significant values among newly hypertensive patients, but there are certain limitations of this study. More studies should be done in newly diagnosed hypertensive patients. Large number of patients should be monitored to get more evidences in this regard. Long term follow up could not be done in this study to monitor their long term tendency towards coagulopathy.

\section{Conclusion}

Study explained strong relationship between hypertension and coagulation parameters. Increased levels of PT and APTT in recently diagnosed hypertensive patients are suggestive of their increased tendency towards atherosclerosis and other hemostatic defects. So basic coagulation screening is very significant to prevent hypertensive patients from unwanted events. Various factors in coagulation cascade are important in development of maintaining hemostatic function. Early detection of any disturbance in coagulation will lead to prevention of life threatening complications. Detection of early stages of damage by screening basic coagulation parameters should be done along with other routine screening to see their predisposition towards unwanted effects.

\section{Acknowledgements}

None.

\section{Conflict of interest}

The author declares no conflict of interest.

\section{References}

1. Muhamedhussein MS, Nagri ZI, Manji KP. Prevalence, risk factors, awareness and treatment and control of hypertension in Mafia Island, Tanzania. International Journal of Hypertension. 2016;2016:1-5.

2. Kusuma YS, Babu BV, Naidu JM. Blood pressure levels among crosscultural populations of Visakhapatnam district, Andhra Pradesh, India. Ann Hum Biol. 2002;29(5):502-512.

3. Bernatova I. Endothelial dysfunction in experimental models of arterial hypertension: cause or consequence? Biomed Res Int. 2014;2014:598271.

4. Singer DR, Kite A. Management of hypertension in peripheral arterial disease: does the choice of drugs matter? Eur J Vasc Endovasc Surg. 2008;35(6):701-708.

5. Appel LJ, Champagne CM, Harsha DW, et al. Effects of comprehensive lifestyle modification on blood pressure control: main results of the PREMIER clinical trial. JAMA. 2003;289(16):2083-2093.

6. Miljic D, Miljic P, Doknic M, et al. Changes in prothrombin and activated partial thromboplastin time during replacement therapy with human recombinant growth hormone in growth hormone deficient adults. Hormones (Athens). 2006;5(3):187-191.

7. Abdollahi A, Shoar N, Shoar S, et al. Extrinsic and intrinsic coagulation pathway, fibrinogen serum level and platelet count in HIV positive patients. Acta Med Iran. 2013;51(7):472-476.

8. Bowman TS, Sesso HD, Gaziano JM. Effect of age on blood pressure parameters and risk of cardiovascular death in Men. Am J Hypertens. 2006;19(1):47-52.

9. Lusis AJ. Atherosclerosis. Nature. 2000;407(6801):233-241.

10. Tabas I, Cardeña GG, Owens GK. Recent insights into the cellular biology of atherosclerosis. J Cell Biol. 2015;209(1):13-22.

11. Adaeze NN, Emeribe AU, Nasiru IA, et al. Evaluation of prothrombin time and activated partial thromboplastin time in hypertensive patients attending a tertiary hospital in Calabar, Nigeria. Advances in Hematology. 2014;2014:1-7.

12. Kamal AH, Tefferi A, Pruthi RK. How to Interpret and Pursue an Abnormal Prothrombin Time, Activated Partial Thromboplastin Time, and Bleeding Time in Adults. Mayo Clin Proc. 2007;82(7):864-873.

13. Hajjar I, Kotchen TA. Trends in prevalence, awareness, treatment, and control of hypertension in the United States, 1988-2000. JAMA. 2003;290(2):199-206.

14. Hinderliter AL, Sherwood A, Craighead LW, et al. The long-term effects of lifestyle change on blood pressure: one-year follow-up of the ENCORE study. Am J Hypertens. 2014;27(5):734-741.

15. Peltzer K, Mafuya NP. Hypertension and associated factors in older adults in South Africa. Cardiovasc J Afr. 2013;24(3):67-71.

16. Reriani MK, Lerman LO, Lerman A. Endothelial function as a functional expression of cardiovascular risk factors. Biomark Med. 2010;4(3):351360.

17. Vanhoutte PM, Feletou M, Taddei S. Endothelium- dependent contractions in hypertension. Br J Pharmacol. 2005;144(4):449-458.

18. Puy C, Tucker EI, Ivanov IS, et al. Platelet-derived short-chain polyphosphates enhance the inactivation of tissue factor pathway inhibitor by activated coagulation factor XI. PLoS One. 2016;11(10):e0165172.

19. Puy C, Tucker EI, Wong ZC, et al. Factor XII promotes blood coagulation independent of factor XI in the presence of long chain polyphosphate. $J$ Thromb Haemost. 2013;11(7):1341-1352. 
20. Puy C, Tucker EI, Matafonov A, et al. Activated factor XI increases the pro-coagulant activity of the extrinsic pathway by inactivating tissue factor pathway inhibitor. Blood. 2015;125(9):1488-1496.

21. Nichols WL, Hultin MB, James AH, et al. von Willebrand disease (VWD): evidence-based diagnosis and management guidelines, the national heart, lung, and blood institute (NHLBI) expert panel report (USA). Haemophilia. 2008;14(2):171-232.
22. Lee AJ. The role of rheological and haemostatic factors in hypertension. J Hum Hypertens. 1997;11(12):767-776.

23. Matsumoto T, Tostes RC, Webb RC. The Role Of Uridine Adenosine Tetraphosphate In The Vascular System. Adv Pharmacol Sci. 2011;2011:435132. 